Article

\title{
Nanostructured Fe-Ni Sulfide: A Multifunctional Material for Energy Generation and Storage
}

\author{
Chen Zhao ${ }^{1}$, Chunyang Zhang ${ }^{1}$, Sanket Bhoyate ${ }^{1}$, Pawan K. Kahol ${ }^{2}$, Nikolaos Kostoglou ${ }^{3}(\mathbb{D}$, \\ Christian Mitterer ${ }^{3}\left(\mathbb{D}\right.$, Steve Hinder ${ }^{4}$, Mark Baker ${ }^{4}$, Georgios Constantinides ${ }^{5}$, \\ Kyriaki Polychronopoulou 6,7,*, Claus Rebholz ${ }^{8}$ (D) and Ram K. Gupta 1,*(D) \\ 1 Department of Chemistry, Pittsburg State University, Pittsburg, KS 66762, USA \\ 2 Department of Physics, Pittsburg State University, Pittsburg, KS 66762, USA \\ 3 Department of Materials Science, Montanuniversität Leoben, 8700 Leoben, Austria \\ 4 Department of Mechanical Engineering Sciences, University of Surrey, Guildford GU27XH, UK \\ 5 Department of Mechanical Engineering and Materials Science and Engineering, Cyprus University of \\ Technology, 3036 Lemesos, Cyprus \\ 6 Department of Mechanical Engineering, Khalifa University of Science and Technology, \\ Abu Dhabi P.O. Box 127788, UAE \\ 7 Center for Catalysis and Separations, Khalifa University of Science and Technology, \\ Abu Dhabi P.O. Box 127788, UAE \\ 8 Department of Mechanical and Manufacturing Engineering, University of Cyprus, 1678 Nicosia, Cyprus \\ * Correspondence: kyriaki.polychrono@ku.ac.ae (K.P.); rgupta@pittstate.edu (R.K.G.)
}

Received: 17 May 2019; Accepted: 6 July 2019; Published: 11 July 2019

\begin{abstract}
Multifunctional materials for energy conversion and storage could act as a key solution for growing energy needs. In this study, we synthesized nanoflower-shaped iron-nickel sulfide (FeNiS) over a nickel foam (NF) substrate using a facile hydrothermal method. The FeNiS electrode showed a high catalytic performance with a low overpotential value of $246 \mathrm{mV}$ for the oxygen evolution reaction (OER) to achieve a current density of $10 \mathrm{~mA} / \mathrm{cm}^{2}$, while it required $208 \mathrm{mV}$ at $10 \mathrm{~mA} / \mathrm{cm}^{2}$ for the hydrogen evolution reaction (HER). The synthesized electrode exhibited a durable performance of up to 2000 cycles in stability and bending tests. The electrolyzer showed a lower cell potential requirement for a FeNiS-Pt/C system $(1.54 \mathrm{~V})$ compared to a standard benchmark $\mathrm{IrO}_{2}-\mathrm{Pt} / \mathrm{C}$ system $(1.56 \mathrm{~V})$ to achieve a current density of $10 \mathrm{~mA} / \mathrm{cm}^{2}$. Furthermore, the FeNiS electrode demonstrated promising charge storage capabilities with a high areal capacitance of $13.2 \mathrm{~F} / \mathrm{cm}^{2}$. Our results suggest that FeNiS could be used for multifunctional energy applications such as energy generation (OER and HER) and storage (supercapacitor).
\end{abstract}

Keywords: FeNiS; electrocatalyst; cyclic voltammetry; supercapacitor; cyclic stability; flexibility

\section{Introduction}

The US Energy Information Administration (EIA) estimates a 28\% growth in total world energy consumption from 2015 to 2040 [1]. Increasing global population has resulting in a dramatic demand for energy in household appliances, portable electronic devices, automobiles, aerospace vehicles and industrial equipment, thus creating an urgent need for clean, renewable energy generation for storage devices [2-8]. Fuel cells and supercapacitors are among the most widely used energy conversion and storage devices $[9,10]$. In order to survive growing needs, multifunctional materials could assist in providing efficient remedial solutions. Thio-spinels are widely used materials for multifunctional energy generation in storage devices [11]. Synergistic chemical composition using different transition metal compounds provides several advantages in terms of tailoring properties and obtaining ultimately 
promising performances for a wide range of applications spanning the environment [12], energy [13] and electrocatalysis [14].

Hydrogen is considered to be an efficient clean energy fuel and can be easily be obtained from water electrolysis [15] through a hydrogen evolution reaction (HER) leading to a high energy density in the order of $141.86 \mathrm{MJ} / \mathrm{kg}$ [7]. On the other hand, oxygen gas produced from an oxygen evolution reaction (OER) through water splitting could serve as an essential candidate for air batteries, fuel cells, or as an environmentally friendly gas $[5,16]$. In theory, based on thermodynamic considerations, water splitting should occur at $1.23 \mathrm{~V}$ (vs. a reversible hydrogen electrode (RHE)); however, in practice this process requires extra potential called overpotential [17]. To overcome this challenge, an efficient catalyst that reduces the reaction overpotential is needed. Several materials such as $\mathrm{IrO}_{2}$, $\mathrm{RuO}_{2}$ and $\mathrm{Pt}$ are used as benchmark catalysts for water electrolysis in the open literature $[18,19]$. However, their industrial applicability is limited due to lower cycle stability and higher cost as they are precious metals-based. Hence, current water catalysis demands a multifunctional catalyst that is environmentally friendly, earth-abundant, highly stable and economically viable to synthesize. Moreover, supercapacitors are among the widely applied energy storage devices most used, along with batteries, due to their high power density, fast charge-discharge rate, safe operation, wide temperature use range and long lifespan $[20,21]$. Current supercapacitor research focuses on achieving high energy density along with high power density $[3,8]$. Transition metal oxides and sulfides are well-known energy storage materials due to their lower costs, higher charge storage capacities and wide availability in nature [22-26].

In this study, nanostructured iron-nickel oxide (FeNiO) and iron-nickel sulfide (FeNiS) were synthesized using a facile hydrothermal method. The synthesized electrodes were used for energy generation and storage in alkaline electrolytes. In the electrocatalytic studies, the FeNiS electrode required a low overpotential for OER $(246 \mathrm{mV})$ and HER $(208 \mathrm{mV})$ at $10 \mathrm{~mA} / \mathrm{cm}^{2}$. Stable performance was observed during both the stability test over 2000 cycles and the bending test of the electrode. The overall water splitting performance was analyzed using a FeNiS-Pt/C system. A lower cell potential of $1.54 \mathrm{~V}$ was required for FeNiS-Pt/C, compared with $1.56 \mathrm{~V}$ for $\mathrm{IrO}_{2}-\mathrm{Pt} / \mathrm{C}$, to achieve the current density of $10 \mathrm{~mA} / \mathrm{cm}^{2}$. The synthesized FeNiS electrode showed promising charge storage capabilities with a high areal capacitance of $13.2 \mathrm{~F} / \mathrm{cm}^{2}$ at a scan rate of $1 \mathrm{mV} / \mathrm{s}$ and $4.9 \mathrm{~F} / \mathrm{cm}^{2}$ at a current density of $5 \mathrm{~mA} / \mathrm{cm}^{2}$. Our study yielded a favorable multifunctional electrode material for energy generation and storage devices.

\section{Results and Discussion}

Due to the amorphous nature of the synthesized samples, X-ray diffraction (XRD) patterns did not show any diffraction peaks. The morphology of the synthesized electrodes was analyzed using scanning electron microscopy (SEM). Figure 1 shows SEM images for the synthesized FeNiO and FeNiS samples grown over nickel foam (NF). FeNiO formed a structure like fused nanosheet balls on the NF surface, as observed in Figure 1a,b. After sulfurization, the sheet structure became more evident with a flower-shaped morphology of FeNiS nanosheets, as shown in Figure 1c,d. Porous nanosheets directly grown over the NF were anticipated to ease the access to the electrolyte and accelerate the electron transport from the nanosheets to the NF substrate, therefore boosting the electrochemical performance.

The XPS survey spectra of FeNiO and sulfurized FeNiO are given in Figure S1. Figures $2 \mathrm{a}-\mathrm{c}$ and $2 \mathrm{~d}-\mathrm{f}$ show the high resolution, core level XPS spectra of the FeNiO and FeNiS surfaces, respectively. The substantial range of iron, nickel and mixed $\mathrm{Fe} / \mathrm{Ni}$ oxide/hydroxide compounds, and the complexity of their photoelectron spectra (including multiplet splitting and satellite features), makes any interpretation of unknown species on both the mixed metal oxide grown from iron and nickel precursor species, and the oxidized metal sulphide, very difficult. Consequently, the XPS spectral interpretation discussed below must be considered within this context, with the interpretation being tentative due the spectral complexity and range of different $\mathrm{Fe} / \mathrm{Ni}$ oxide/hydroxide- and sulphur-containing species potentially present at the surface. The work of the Surface Science Western group is very useful in understanding 
the complex Fe and Ni 2p peak shapes shown in Figure 2 [27-30]. Our XPS Fe 2p and Ni 2p peak fits are indicative, and for a greater understanding of the Fe $2 p$ and Ni $2 p$ peak structure we refer the reader to the work mentioned above [27-30].

Considering first the FeNiO surface, the Fe:Ni ratio determined from the XPS measurements was 1:2.8, so the stoichiometry of this catalyst was $\mathrm{Ni}_{2.8} \mathrm{FeO}_{x}$. Stoichiometries of Fe:Ni between 1:2 and 1:2.6 have been reported by other authors for $\mathrm{FeNiO}_{x}$ when using a precursors molar ratio of 1:1 [31], so our value of 1:2.8 was not dissimilar from previous work. The binding energy of the $\mathrm{Ni} 2 \mathrm{p}_{3 / 2}$ and Ni $2 \mathrm{p}_{1 / 2}$ peaks are observed at 856.2 and $873.5 \mathrm{eV}$, respectively (Figure $2 \mathrm{~b}$ ). The peak fit shows that although the $\mathrm{Ni} 2 \mathrm{p}_{3 / 2}$ maximum peak intensity arises at $856.2 \mathrm{eV}$, there are clearly two components contributing to this peak, with the presence of a lower binding energy component at $854.7 \mathrm{eV}$ in addition to a higher binding energy component. A narrow linewidth peak for this lower binding energy component is indicative of $\mathrm{Ni}^{2+}$ oxide species $[27,28]$. There is also a strong broad satellite peak at $861.8 \mathrm{eV}$ and two small satellite components at higher binding energies. The component binding energy shifts, FWHMs and general peak fit are in excellent agreement with that of $\mathrm{NiFe}_{2} \mathrm{O}_{4}$, given by Biersinger et al. [29], the only deviation being the intensity of the $856.2 \mathrm{eV}$ component, which is higher in Figure $2 \mathrm{~b}$ compared to the standard $\mathrm{NiFe}_{2} \mathrm{O}_{4}$ [29]. This deviation may have arisen from the variation in the composition of this catalyst compared with the $\mathrm{NiFe}_{2} \mathrm{O}_{4}$ standard, or from the presence of other $\mathrm{Ni}^{2+} / \mathrm{Ni}^{3+}$ species present at the surface such as $\mathrm{OH}^{-}$[27]. The presence of hydroxide species at the surface can be seen by the higher binding energy $\mathrm{OH}^{-}$component at $531.6 \mathrm{eV}$ in addition to oxide, $\mathrm{O}^{2-}$, at $530.0 \mathrm{eV}$ in the $\mathrm{O} 1 \mathrm{~s}$ spectrum (Figure 2c).

The binding energy of the Fe $2 \mathrm{p}_{3 / 2}$ and Fe $2 \mathrm{p}_{1 / 2}$ peaks (Figure $2 \mathrm{a}$ ) occur at 711.7 and $724.7 \mathrm{eV}$, respectively. Such binding energies indicate that the iron was in an $\mathrm{Fe}^{3+}$ oxidation state. However, compared to the Ni $2 p$ spectrum, the peak positions and general peak shape of the Fe $2 p$ spectrum are not so consistent with the spectrum for $\mathrm{NiFe}_{2} \mathrm{O}_{4}$ given by Biersinger et al. [29]. In particular, there is increased intensity between the $2 p_{3 / 2}$ and $2 p_{1 / 2}$ peaks for the spectrum shown in Figure $2 a$ compared with standard $\mathrm{NiFe}_{2} \mathrm{O}_{4}$. This increased intensity can be attributed to the presence of the $\mathrm{Ni} \mathrm{L} \mathrm{M}_{2,3} \mathrm{M}_{4,5}\left({ }^{1} \mathrm{P}\right)$ Auger peak at $\sim 712 \mathrm{eV}$. There is also a Ni Auger $\mathrm{L}_{3} \mathrm{M}_{2,3} \mathrm{M}_{4,5}\left({ }^{3} \mathrm{P}\right)$ peak at $\sim 706 \mathrm{eV}$, which is the source of the broad shoulder to the low binding energy side of the Fe $2 p_{3 / 2}$ peak. This is in agreement with the Ni-rich nature of this mixed metal oxide, and the increased spectral intensity between the Fe $2 p_{3 / 2}$ and $2 p_{1 / 2}$ peaks has also been observed for a $\mathrm{Ni}_{6} \mathrm{Fe}_{4} \mathrm{O}_{\mathrm{x}}$ catalyst reported by Smith et al. [31]. The presence of the $\mathrm{Ni}_{3} \mathrm{M}_{2,3} \mathrm{M}_{4,5}$ Auger peaks make peak-fitting the Fe $2 p$ peak very difficult. There are also $\mathrm{Fe}^{3+}$ satellite peaks at around $8.5 \mathrm{eV}$ from the main $2 \mathrm{p}_{3 / 2} / 2 \mathrm{p}_{1 / 2}$ peaks [30].

For the FeNiS surface, the dominant peaks for the Fe 2p (Figure 2d) and Ni 2p (Figure 2e) spectra are again associated with the presence of surface oxides and, as for the FeNiO surfaces, show binding energies of $\sim 712$ and $\sim 856 \mathrm{eV}$ for the $\mathrm{Fe} 2 \mathrm{p}_{3 / 2}$ and $\mathrm{Ni} 2 \mathrm{p}_{3 / 2}$ peaks, respectively. Oxidation of metal sulphides when exposed to air or water is well-known [32-35] and result from the higher free energy of formation to form the metal oxides/hydroxides/sulphates. The Fe $2 p$ spectrum shows no clear evidence of an iron sulphide peak at lower binding energies than the oxide/hydroxide peaks. However, the $\mathrm{Ni}$ Auger $\mathrm{L}_{3} \mathrm{M}_{2,3} \mathrm{M}_{4,5}\left({ }^{3} \mathrm{P}\right)$ broad shoulder does have a slightly different shape than that of $\mathrm{FeNiO}$, and includes a peak at $707.5 \mathrm{eV}$ that gives rise to a better peak fit. In their work on FeNiS, Piontek et al. [36] observed a small peak at $707.2 \mathrm{eV}$, which they ascribed to $\mathrm{FeS}_{2}$. This binding energy is consistent with others reported for $\mathrm{FeS}_{2}$ [33]. Previous careful XPS analysis by Buckley and Woods [34,35] has shown that the un-oxidized surface of $\mathrm{Fe}_{0.89} \mathrm{~S}$ exhibits a $\mathrm{Fe} 2 \mathrm{p}_{3 / 2}$ binding energy of 707.5-708.0 eV, but oxidation in air and water occurs very rapidly, leading to a shift in the binding energy to $711 \mathrm{eV}$. Consequently, we consider that there a small iron sulphide peak that was present in our Fe $2 p$ spectrum for FeNiS (Figure 2d) at 707.5 eV. The Ni 2p spectrum (Figure 2e) shows a clearer peak at $\sim 853.0 \mathrm{eV}$, attributable most probably to $\mathrm{NiS}[37,38]\left(\mathrm{NiS}_{2}\right.$ is reported to have a slightly higher binding energy of $853.6 \mathrm{eV}[39])$.

The $S 2 p$ spectrum found in Figure $2 \mathrm{f}$ is complex and very similar to that observed by Piontek et al. for FeNiS catalysts [36]. There are three different chemical states given in the peak fit, sulphide, 
oxysulphide and sulphate. $S 2 p_{3 / 2}$ and $S 2 p_{1 / 2}$ peaks are given for all the three different chemical states and in each case there are Fe (lower binding energy) and Ni (higher binding energy) peaks for each chemical state (as reported in the literature for Fe/Ni sulphides and Fe/Ni sulphates). Thus, there are 12 peaks included in the peak fit. The broad higher binding energy $S 2 p$ peak (comprised of four components, numbered 9-12) centered at $\sim 168.5 \mathrm{eV}$ is easily identified and corresponds to the $S$ $2 p_{3 / 2} / S 2 p_{1 / 2}$ peaks for $\mathrm{Fe} / \mathrm{Ni}$ sulphate species. The higher intensity lower binding energy $\mathrm{S} 2 \mathrm{p}$ peak envelope (components 1-4) is again comprised of two $S$ chemical states, each with a $S 2 p_{3 / 2}$ and $S 2 p_{1 / 2}$ doublet. Peak fitting shows the binding energies of these two main $S 2 p_{3 / 2}$ components peaks to be $161.3 \mathrm{eV}$ (peak 1) and $162.4 \mathrm{eV}$ (peak 3), which are both generally consistent with the presence of a metal sulphide compound. Piontek et al. [36] proposed that these peaks correspond to oxysulphide species. However, oxidation in water or air has previously shown the formation only of oxide or sulphate species, not oxysulphide [32,33]. Oxysulphide would be expected to occur at a higher binding energy than typical metal sulphides and, as we propose below, such species are only likely to occur as a thin layer at the interface between the sulphide and sulphate, thus giving rise to relatively small intensity peaks. The higher intensity $S 2 p_{3 / 2}$ peak at $162.4 \mathrm{eV}$ is in very good agreement with that of NiS reported by others [38,39]. The lower binding energy $S 2 p_{3 / 2}$ peak at $161.2 \mathrm{eV}$ agrees well with the value of $161.1 \mathrm{eV}$ given by Buckley and Woods for $\mathrm{Fe}_{0.89} \mathrm{~S}[34,35]$. The presence of spectral intensity between the sulphide and sulphate peaks (components 5-8) most probably represents oxysulphide $\mathrm{Ni}$ and $\mathrm{Fe}$ species at the interface between the sulphide and sulphate, but could also be caused by Ni/Fe-deficient sulphide at the surface of the FeNiS, resulting from oxidation of the metallic species [34].

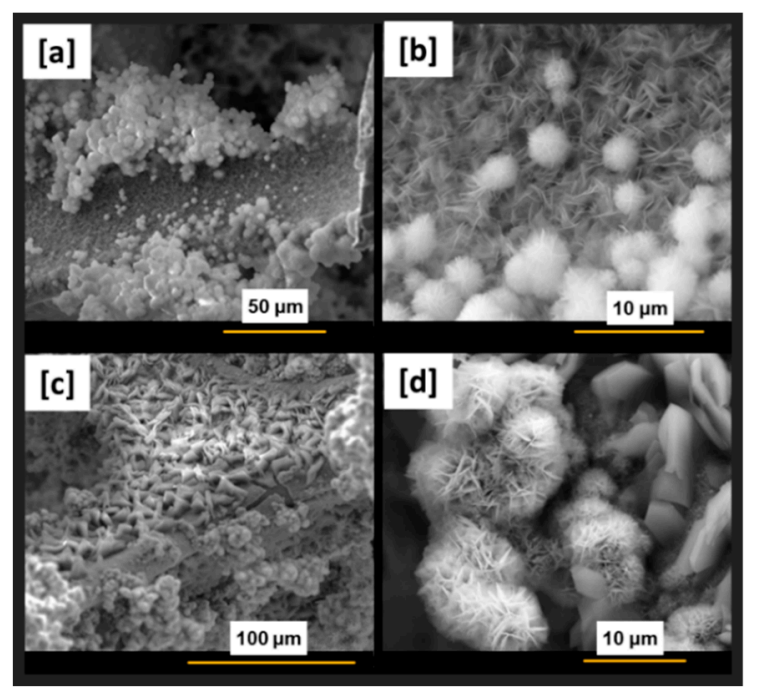

Figure 1. SEM images of $(\mathbf{a}, \mathbf{b}) \mathrm{FeNiO}$ and $(\mathbf{c}, \mathbf{d}) \mathrm{FeNiS}$.

The presence of a relatively strong FeS peak in the S $2 p$ spectrum, but a very weak peak in the Fe $2 p$ spectrum, would appear to be inconsistent. However, S $2 p$ photoelectrons have higher kinetic energies compared to Fe $2 p$ photoelectrons. Calculations of the difference in electron attenuation length based on the universal equation by Seah [40] showed the S 2p photoelectrons to have an analysis depth $50 \%$ greater than the Fe $2 p$ photoelectrons. Consequently, since the sulphide was buried beneath the surface oxide/hydroxide, this difference in analysis depth can explain the absence of the FeS peak in the Fe $2 p$ spectrum but its presence in the $S 2 p$ spectrum. However, NiS appears in the Ni $2 p$ spectrum (with the $\mathrm{Ni} 2 \mathrm{p}$ photoelectrons exhibiting a lower kinetic energy than the Fe $2 p$ photoelectrons). This would indicate that the outer surface of the mixed metal sulphide is rich in Ni and depleted in Fe. Furthermore, the results of Piontek et al. also concur with this interpretation [36]. Their XPS Fe, Ni and S spectra are generally very similar to those observed here, apart from the presence of a weak Fe-S peak. However, in the study by Piontek et al., the Ni-S peak was substantially stronger than their weak Fe-S peak, even for samples with an Fe:Ni ratio of 2:1, and for samples where the Fe:Ni ratio was reported to be 
1:1 the Ni-S peak was even stronger than the Ni oxide/hydroxide peaks [36]. For our catalysts, the Fe:Ni ratio in the metal sulphide determined from the $S 2 p$ peak was 1:1.3, thus we would expect a significantly weaker Fe-S peak compared to that given by Piontek et al., and our NiS peak is of a much lower intensity than the Ni oxide/hydroxide peaks. Thus, there is greater oxidation of our mixed-metal sulphide compared to the catalysts synthesized by Piontek et al. [36], and we would expect a particularly weak FeS peak considering the sulphide to be Ni rich.

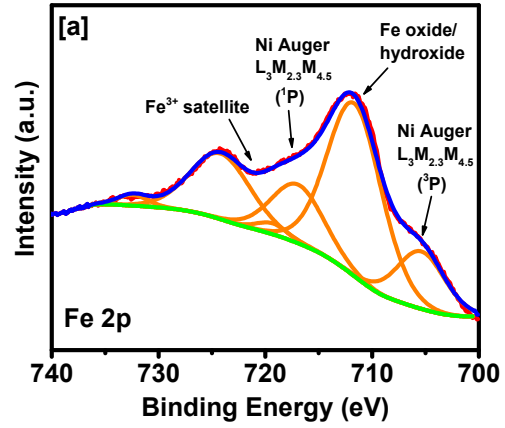

(a)

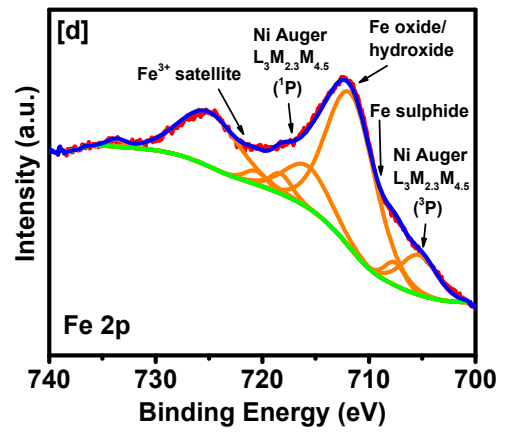

(d)

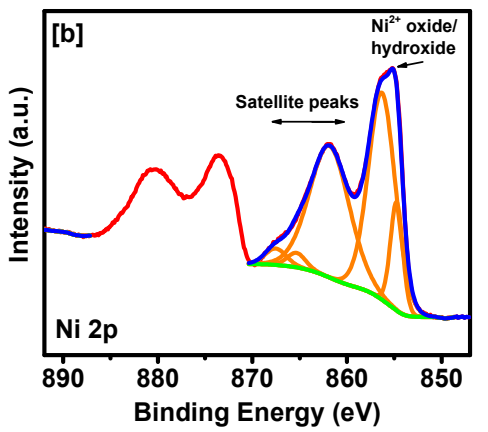

(b)

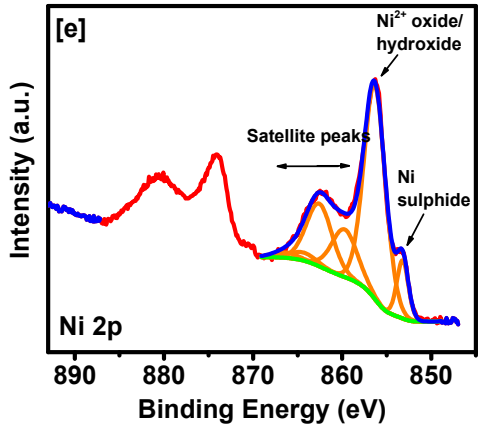

(e)

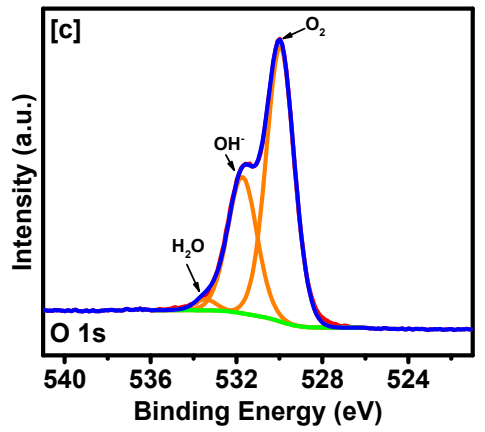

(c)

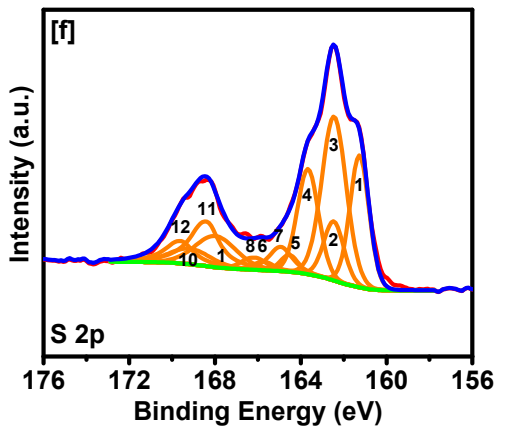

(f)

Figure 2. Peak-fitted XPS spectra of $(\mathbf{a}-\mathbf{c}) \mathrm{FeNiO}$ and (d-f) FeNiS.

Linear scan voltammetry (LSV) was used to analyze the water-splitting reaction using synthesized catalytic electrodes. Figure 3a summarizes the catalytic performance of all the catalyst electrodes. It is essential to have a lower overpotential value for better catalytic performance along with a low Tafel slope to ensure better reaction kinetics [41,42]. The lowest overpotential of $246 \mathrm{mV}$ was observed for FeNiS compared to FeNiO $(277 \mathrm{mV}), \mathrm{IrO}_{2}(309 \mathrm{mV})$ and $\mathrm{NF}(410 \mathrm{mV})$ at a current density of $10 \mathrm{~mA} / \mathrm{cm}^{2}$. FeNiS showed comparable reaction kinetics with a Tafel slope of $49 \mathrm{mV} /$ dec compared to the benchmark $\mathrm{IrO}_{2}$ catalyst shown in Figure 3b. Moreover, our results are comparable to other previously reported studies, as summarized in Table S1 (Supplementary Materials). The better electrocatalytic performance could be further correlated to the active electrochemical surface area of the catalytic electrode. Highly porous nanostructured sheets of $\mathrm{NiFeS}$ would allow easy access to the electrolyte and an easy escape of oxygen from the electrode resulting in lower overall series resistance (Figure S2a). The stability of the OER catalyst electrode was studied using a stability test, bending test and chronoamperometry (CA) test. Figure 3c,d shows the excellent stability of the catalytic electrode after the 2000 cycle and bending tests at a $45^{\circ}$ angle. Furthermore, the Nyquist plot at $0.5 \mathrm{~V}$ shows no significant change in resistance of the overall system, suggesting an excellent catalytic stability of the FeNiS electrode. Moreover, a chronoampere study presented in Figure S2d also showed stable electrode performance with minimal loss in current even after $15 \mathrm{~h}$. Thus, from the overall study, FeNiS shows promising characteristics as an OER catalyst to be used as a low-cost alternative with respect to benchmark catalysts such as $\mathrm{IrO}_{2}$. 


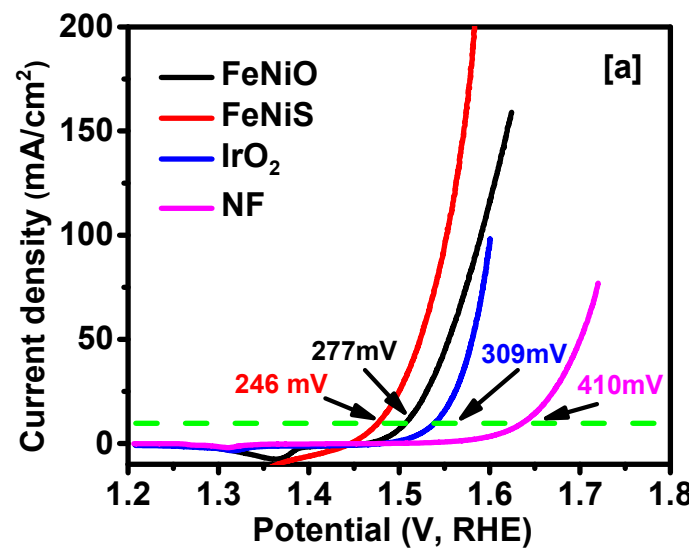

(a)

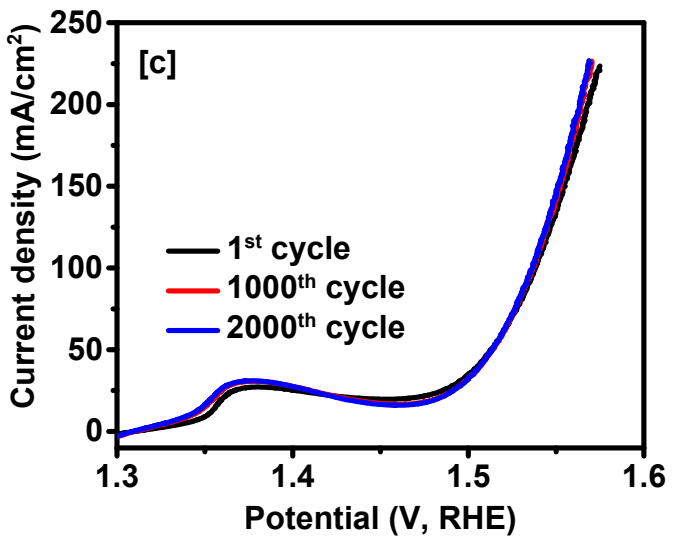

(c)

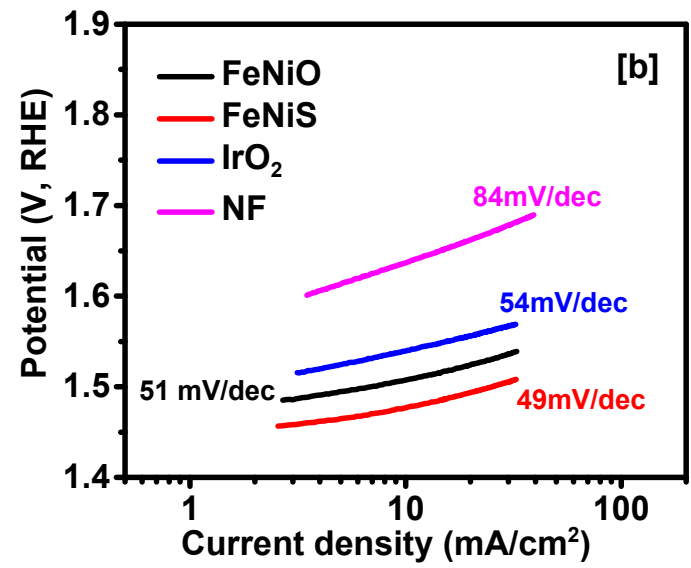

(b)

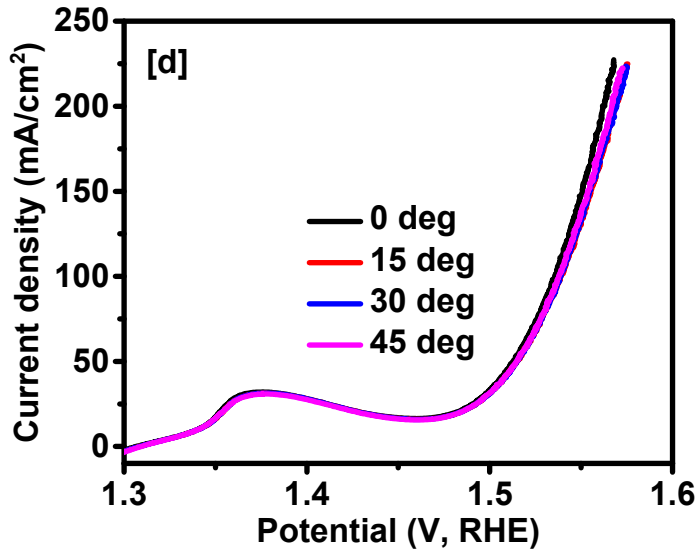

(d)

Figure 3. (a) Polarization curves for OER, (b) Tafel slopes for FeNiO, FeNiS, $\mathrm{IrO}_{2}$ and NF, (c) LSV curves during stability test for OER and (d) LSV curves at different bending angles.

The electrocatalytic properties for the HER reaction were analyzed for all electrodes using the LSV test. It can be understood from Figure $4 \mathrm{a}$ that FeNiS shows a low overpotential value of $208 \mathrm{mV}$, while $\mathrm{FeNiO}$ requires an overpotential of $253 \mathrm{mV}$ to achieve a current density of $10 \mathrm{~mA} / \mathrm{cm}^{2}$. Although FeNiS shows overpotential values comparable to those previously reported, competing with the catalytic properties of the benchmark $\mathrm{Pt} / \mathrm{C}$ catalyst for HER still remains a challenge (Table S2). Furthermore, the Tafel slopes for FeNiS, FeNiO and Pt/C were observed as 109, 129 and $56 \mathrm{mV} / \mathrm{dec}$, respectively (Figure $4 \mathrm{~b}$ ). As observed in the previous section, catalytic electrodes should perform in a stable manner when used as HER catalyst. Figure 4c clearly shows the LSV curves after the 1st, 1000th and 2000th cycles, with almost no deterioration in catalytic properties. Similar behavior was observed from LSV curves during bending tests at different angles (Figure 4d). The Nyquist plots obtained from electrochemical impedance spectroscopy (EIS) at $-1.3 \mathrm{~V}$ during both the stability and bending tests are given in Figure S3a,b. The charge transfer resistance showed very small variation upon stability and bending tests. Furthermore, all electrodes showed stable performance during the $15 \mathrm{~h}$ chronoamperometry test, as given in Figure S3c.

An electrolyzer cell was fabricated to study water splitting using a two-electrode system. In the previous three-electrode system, the OER study of FeNiS showed a lower overpotential for $\mathrm{IrO}_{2}$, which is one of the standard benchmark catalysts, while in the HER test obtaining an overpotential lower than the benchmark $\mathrm{Pt} / \mathrm{C}$ catalyst still remains a challenge. From our study, we observed that $\mathrm{IrO}_{2}$ can only perform well as an OER catalyst and $\mathrm{Pt} / \mathrm{C}$ as a HER catalyst (Figure S4). Hence, in the two electrode study, we used FeNiS as the OER catalyst along with $\mathrm{Pt} / \mathrm{C}$ as the HER catalyst (Figure 5). The comparison was made with $\mathrm{IrO}_{2}$ and $\mathrm{Pt}$ as standard catalysts. It was observed that FeNiS-Pt/C 
required a lower potential of $1.54 \mathrm{~V}$ compared to $\mathrm{IrO}_{2}-\mathrm{Pt} / \mathrm{C}(1.56 \mathrm{~V})$ to achieve a current density of $10 \mathrm{~mA} / \mathrm{cm}^{2}$. The reported results are lower compared to the majority of previously reported values in alkaline media, as observed in Table S3. Furthermore, FeNiS-Pt/C showed stable performance during continuous water electrolysis for $16 \mathrm{~h}$, as shown in Figure $5 \mathrm{~b}$.

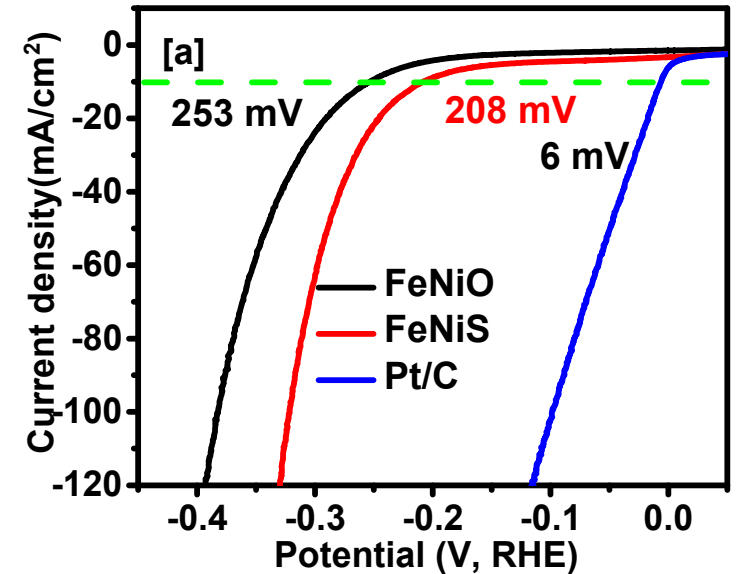

(a)

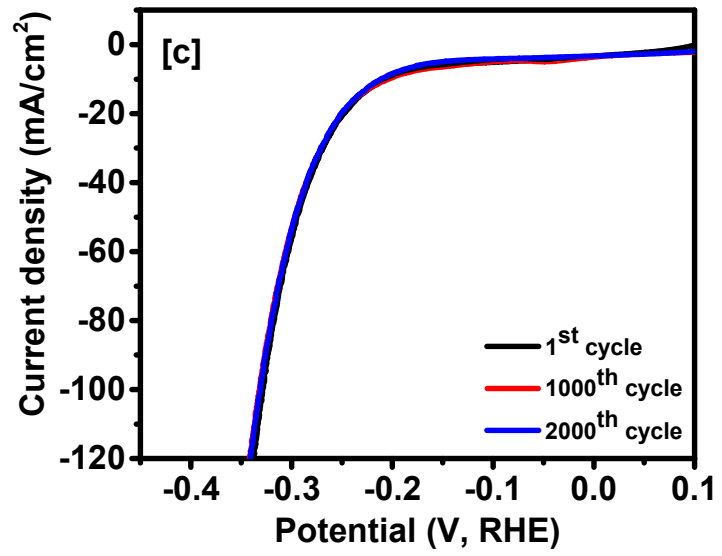

(c)

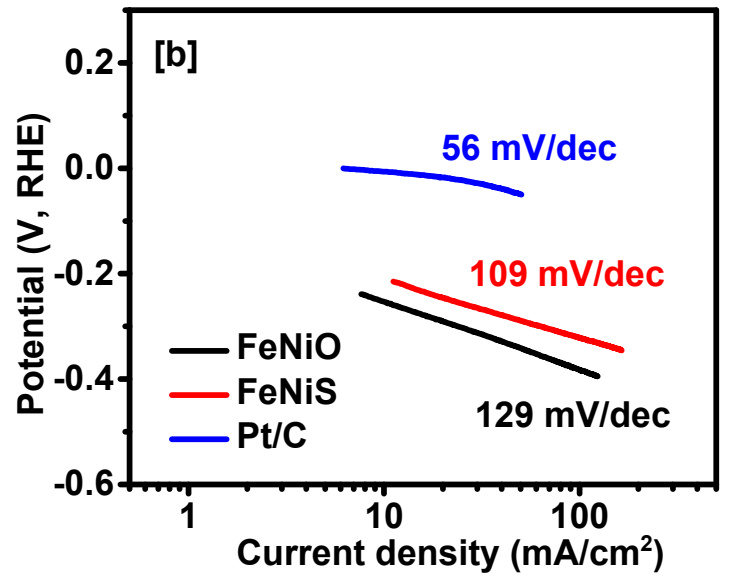

(b)

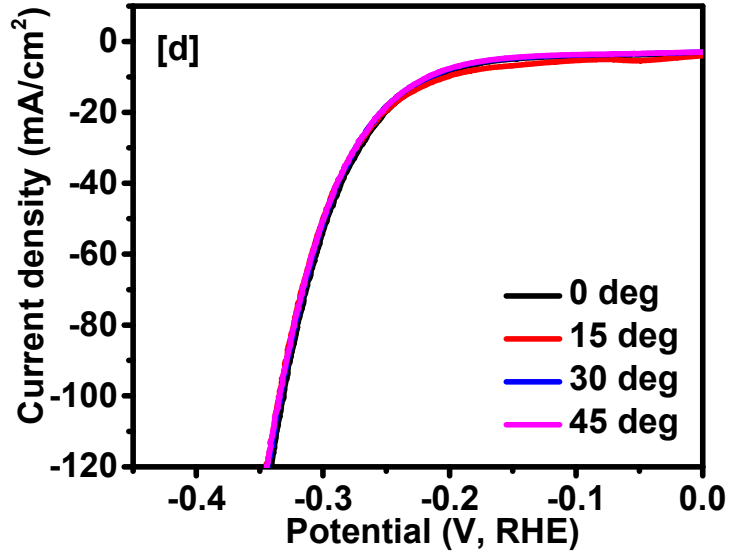

(d)

Figure 4. (a,b) Polarization curves and Tafel slopes for FeNiO, FeNiS and Pt/C in HER region, (c) LSV curves after different stability cycles and (d) LSV curves at different bending angles.

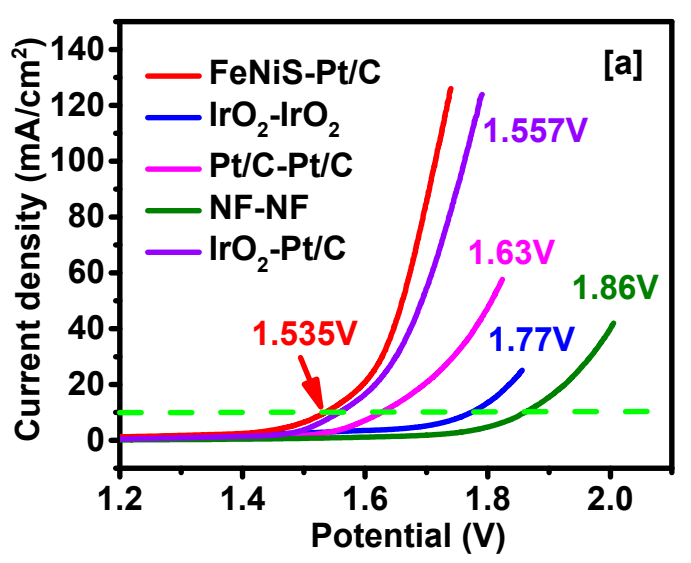

(a)

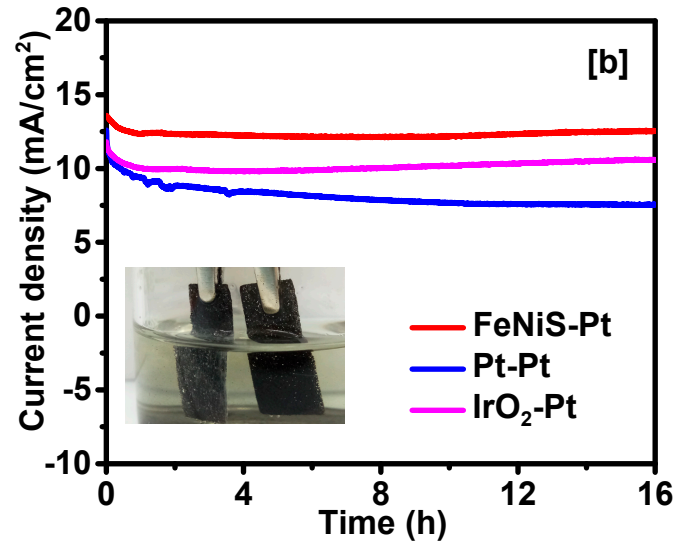

(b)

Figure 5. Results for overall water splitting using two electrode system: (a) polarization curves for FeNiS-Pt/C, $\mathrm{IrO}_{2}-\mathrm{IrO}_{2}, \mathrm{Pt} / \mathrm{C}-\mathrm{Pt} / \mathrm{C}, \mathrm{NF}-\mathrm{NF}$ and $\mathrm{IrO}_{2}-\mathrm{Pt} / \mathrm{C}$ and (b) chronoamperometry plots for FeNiS-Pt/C, Pt/C-Pt/C and $\mathrm{IrO}_{2}-\mathrm{Pt} / \mathrm{C}$. 
The charge storage behavior of the synthesized samples was analyzed using cyclic voltammetry (CV) and galvanostatic charge-discharge (GCD) test. The relationship of the specific capacitance at different scan rates can be observed in Figure 6a. The highest specific capacitance of $13.2 \mathrm{~F} / \mathrm{cm}^{2}$ was observed for the FeNiS sample at a scan rate of $1 \mathrm{mV} / \mathrm{s}$. It can be clearly seen from the $\mathrm{CV}$ curves in Figure $6 \mathrm{~b}$ that FeNiS showed the highest area under $\mathrm{CV}$ curves at $2 \mathrm{mV} / \mathrm{s}$ compared to $\mathrm{FeNiO}$ and $\mathrm{NF}$, leading to higher capacitance values. The capacitance increases with decreasing scan rates, which could be due to sufficient time provided for the faradic reaction representing the pseudocapacitive behavior (Figure S5a) $[43,44]$. The results of the galvanostatic charge-discharge test are represented by the relationship between specific capacitance with respect to the current density in Figure 6c. The discharge time for the FeNiS electrode was significantly higher compared to $\mathrm{FeNiO}$ and NF, as summarized in Figure 6d. As the charging current decreases, an improvement is observed in the charging and discharging time of the FeNiS sample (Figure S5b). In comparison, Li, Y. et al. observed $78.5 \%$ capacitance retention after 3000 cycles for Ni-Co sulfides [45]. In our study, the FeNiS showed a performance with $77.3 \%$ retention after 5000 cycles in charge-discharge measurements and comparable capacitance results to several other reports (Table S4 and Figure S5c).

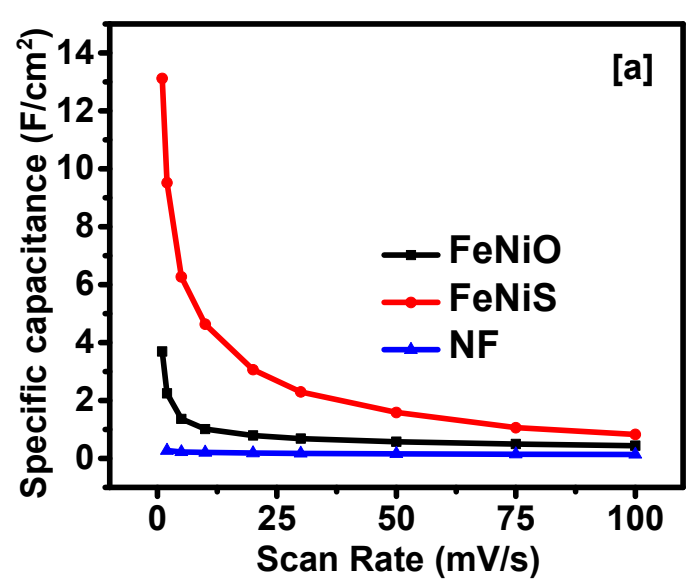

(a)

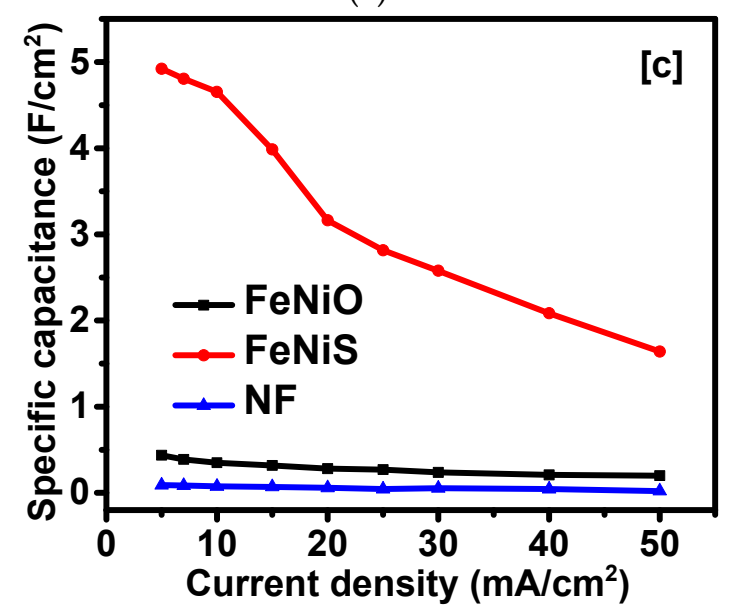

(c)

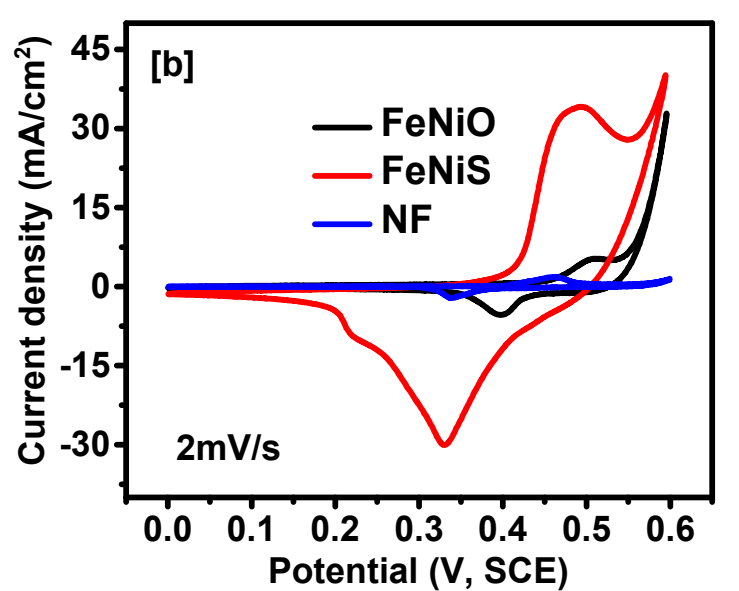

(b)

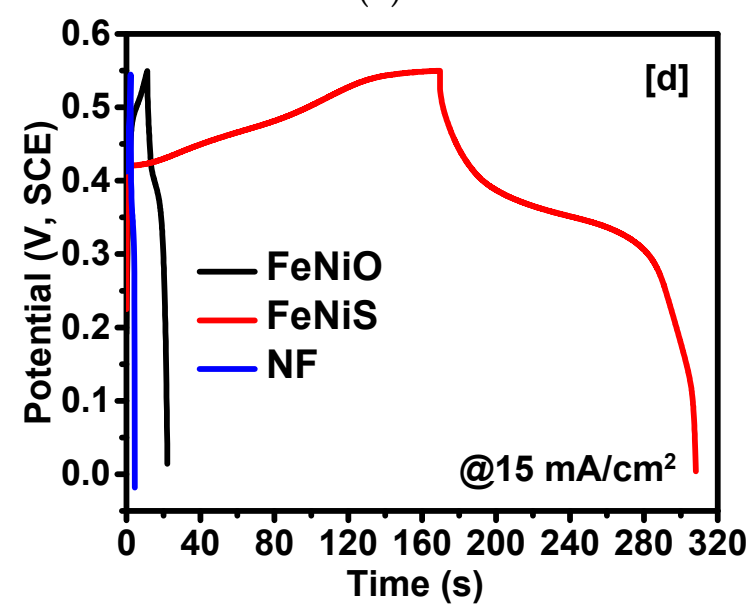

(d)

Figure 6. Charge storage behavior for FeNiS, FeNiO and NF: (a) specific capacitance vs. scan rate, (b) CV curves, (c) specific capacitance vs. current density and (d) charge discharge curves. 


\section{Experimental Details}

\subsection{Preparation of FeNiO and FeNiS Electrodes}

In a typical process, $3 \mathrm{mmol}$ of ammonium fluoride, $7.5 \mathrm{mmol}$ of urea, $1 \mathrm{mmol}$ of $\mathrm{Ni}\left(\mathrm{NO}_{3}\right)_{2} \cdot 6 \mathrm{H}_{2} \mathrm{O}$ and $\mathrm{Fe}\left(\mathrm{NO}_{3}\right)_{3} \cdot 9 \mathrm{H}_{2} \mathrm{O}$ were dissolved in $30 \mathrm{~mL}$ DI-water. The solution was then transferred into a $50-\mathrm{mL}$ Teflon-lined autoclave reactor. The precleaned Ni foam (NF) was immersed in this solution, and the reaction was carried out at $120^{\circ} \mathrm{C}$ for $6 \mathrm{~h}$. The obtained NF was washed several times with water and ethanol. Similarly, the precipitates were washed and collected using a centrifuge at 10,000 rpm for $10 \mathrm{~min}$. Resultant samples were dried at $60^{\circ} \mathrm{C}$ for $12 \mathrm{~h}$ under vacuum. Further, FeNiO was obtained by calcining the samples at $350{ }^{\circ} \mathrm{C}$ for $2 \mathrm{~h}$ at a heating rate of $5^{\circ} \mathrm{C} / \mathrm{min}$.

For the preparation of $\mathrm{FeNiS}, 500 \mathrm{mg}$ thiourea was dissolved in $30 \mathrm{~mL}$ ethanol. The solution was transferred into a $50 \mathrm{~mL}$ Teflon-line autoclave reactor containing the non-calcined samples from the previous reaction. The reaction was carried out at $140^{\circ} \mathrm{C}$ for $12 \mathrm{~h}$. The obtained NF coated with FeNiS and the precipitates were washed and dried under vacuum. The comparison was carried out using commercial samples of $\mathrm{IrO}_{2}$ and Pt-C coated over NF.

\subsection{Characterization}

A Shimadzu X-ray diffractometer using $\mathrm{CuK} \alpha_{1}(\lambda=1.5406 \AA)$ radiation was used to study the crystal structure of the synthesized samples. The microstructural/morphological features of the FeNiO and FeNiS samples, hydrothermally deposited on Ni foams, were studied using a Quanta 200 SEM (FEI, Hillsboro, OR, USA) at an acceleration voltage of $20 \mathrm{kV}$. XPS analysis was performed over the scrap-out powder from the Ni foam electrode using a ThermoFisher Scientific Instruments K-Alpha ${ }^{+}$ spectrometer (East Grinstead, UK) to study the chemical composition of the synthesized samples. The XPS instrument was equipped with a monochromated $\mathrm{Al} \mathrm{K \alpha}$ radiation source $(\mathrm{h} v=1486.6 \mathrm{eV})$ and an X-ray spot of $\sim 400 \mu \mathrm{m}$ in radius. Survey spectra were acquired with a pass energy of $200 \mathrm{eV}$, while high-resolution core level spectra for all elements were acquired with a pass energy of $50 \mathrm{eV}$. The electrochemical characterization studies of the electrodes were carried out using a standard three-electrode system and a two-electrode system using a Versastat 4-500 electrochemical workstation (Princeton Applied Research, Oak Ridge, TN, USA). In the three-electrode system, synthesized samples were used as the working electrodes, a saturated calomel electrode (SCE) was used as the reference electrode and a graphitic rod was used as the counter electrode. The electrocatalytic behavior of the synthesized electrodes was measured in $1 \mathrm{M} \mathrm{KOH}$ electrolyte using linear sweep voltammetry, cyclic voltammetry, chronoamperometry (CA) and electrochemical impedance spectroscopy (EIS). The charge storage behavior of the electrodes was measured in $3 \mathrm{M} \mathrm{KOH}$ using a CV, GCD and EIS. The EIS measurements were performed in a frequency range of $0.05 \mathrm{~Hz}$ to $10 \mathrm{kHz}$, with an applied AC amplitude of $10 \mathrm{mV}$. The average weight loading of the material in all the electrodes was $1.2 \mathrm{mg} / \mathrm{cm}^{2}$.

\section{Conclusions}

In conclusion, we have synthesized nano-flower shaped FeNiS on Ni foam using a facile hydrothermal method as a multifunctional electrode material for energy conversion and storage devices. The FeNiS electrode exhibited excellent stability and flexibility along with higher catalytic activity providing low overpotential values for the OER and HER reactions. Moreover, it showed competitive performance when used as the OER electrode in an electrolyzer device study over the standard benchmark $\mathrm{IrO}_{2}$ system. Although competing with $\mathrm{Pt} / \mathrm{C}$ as HER catalyst still remains a challenge, FeNiS showed a promising HER activity. The FeNiS electrode displayed acceptable charge storage capabilities to be used for supercapacitor materials. A high areal capacitance of $13.2 \mathrm{~F} / \mathrm{cm}^{2}$ was obtained at a scan rate of $1 \mathrm{mV} / \mathrm{s}$. From our study, we report a cost-effective multifunctional electrode material for energy conversion and storage devices. 
Supplementary Materials: The following are available online at http://www.mdpi.com/2073-4344/9/7/597/s1, Figure S1: XPS survey spectra of (a) FeNiO and (b) sulfurized FeNiO. Figure S2: (a) Nyquist plot for all the OER catalytic electrodes at $0.5 \mathrm{~V}$, (b) Nyquist plot at different stability cycles at $0.5 \mathrm{~V}$, (c) Nyquist plot at different bending angles at $0.5 \mathrm{~V}$, and (d) chronoamperometry. Figure S3: (a) Nyquist plot at different stability cycles at -1.3 $\mathrm{V}$, (b) Nyquist plot at different bending angles at $-1.3 \mathrm{~V}$ and, (c) chronoamperometry. Figure S4: LSV polarization curves for Pt/C and $\mathrm{IrO}_{2}$ : (a) HER and (b) OER. Figure S5: Characteristics of FeNiS: (a) CV curves, (b) GCD curves and (c) cyclic stability plot for FeNiS sample using GCD measurements. Table S1. Comparison of OER catalysis with other reports. Table S2. Comparison of HER catalysis with other reports. Table S3. Comparison of overall water splitting. Table S4. Comparison of supercapacitor performance of some recently reported results.

Author Contributions: R.K.G. conceived the project, designed the experiments, interpreted the data, and finalized the manuscript. The first draft of the manuscript was written by C.Z. (Chen Zhao), C.Z. (Chunyang Zhang) and S.B. C.Z. (Chen Zhao), C.Z. (Chunyang Zhang) and S.B. performed all the electrochemical measurements, analyzed the data and recorded the XRD patterns. SEM images were recorded by G.C. M.B. and S.H. provided XPS data. P.K.K., N.K., C.M., C.R., P.K.K. and K.P. reviewed and finalized the manuscript.

Funding: This research received no external funding. The APC was funded by the Abu Dhabi Education and Knowledge (ADEK) Department, Award for Research Excellence, AARE 2017.

Acknowledgments: R.K.G. expresses his sincere acknowledgment to the Polymer Chemistry Program and Kansas Polymer Research Center, Pittsburg State University, for providing financial and research support to complete this project.

Conflicts of Interest: The authors declare no conflict of interest.

\section{References}

1. EIA. International Energy Outlook 2017 Overview; U.S. Energy Information Administration: Washington, DC, USA, 2017. [CrossRef]

2. Tao, S.; Ru, M.Y.; Du, W.; Zhu, X.; Zhong, Q.R.; Li, B.G.; Shen, G.F.; Pan, X.L.; Meng, W.J.; Chen, Y.L.; et al. Quantifying the rural residential energy transition in China from 1992 to 2012 through a representative national survey. Nat. Energy 2018, 3, 567-573. [CrossRef]

3. Bhoyate, S.; Mensah-Darkwa, K.; Kahol, P.K.; Gupta, R.K. Recent Development on Nanocomposites of Graphene for Supercapacitor Applications. Curr. Graphene Sci. 2017, 1, 26. [CrossRef]

4. Bhoyate, S.; Kahol, P.K.; Sapkota, B.; Mishra, S.R.; Perez, F.; Gupta, R.K. Polystyrene activated linear tube carbon nanofiber for durable and high-performance supercapacitors. Surf. Coat. Technol. 2018, 345, 113-122. [CrossRef]

5. Ranaweera, C.K.; Zhang, C.; Bhoyate, S.; Kahol, P.K.; Ghimire, M.; Mishra, S.R.; Perez, F.; Gupta, B.K.; Gupta, R.K. Flower-shaped cobalt oxide nano-structures as an efficient, flexible and stable electrocatalyst for the oxygen evolution reaction. Mater. Chem. Front. 2017, 1, 1580-1584. [CrossRef]

6. Bhoyate, S.; Ranaweera, C.K.; Zhang, C.; Morey, T.; Hyatt, M.; Kahol, P.K.; Ghimire, M.; Mishra, S.R.; Gupta, R.K. Eco-Friendly and High Performance Supercapacitors for Elevated Temperature Applications Using Recycled Tea Leaves. Glob. Chall. 2017, 1, 1700063. [CrossRef]

7. Zhang, C.; Wang, Z.; Bhoyate, S.; Morey, T.; Neria, B.L.; Vasiraju, V.; Gupta, G.; Palchoudhury, S.; Kahol, P.K.; Mishra, S.R.; et al. $\mathrm{MoS}_{2}$ Decorated Carbon Nanofibers as Efficient and Durable Electrocatalyst for Hydrogen Evolution Reaction. C 2017, 3, 33. [CrossRef]

8. Adhikari, H.; Ghimire, M.; Ranaweera, C.K.; Bhoyate, S.; Gupta, R.K.; Alam, J.; Mishra, S.R. Synthesis and electrochemical performance of hydrothermally synthesized $\mathrm{Co} 3 \mathrm{O} 4$ nanostructured particles in presence of urea. J. Alloy. Compd. 2017, 708, 628-638. [CrossRef]

9. Candelaria, S.L.; Shao, Y.; Zhou, W.; Li, X.; Xiao, J.; Zhang, J.-G.; Wang, Y.; Liu, J.; Li, J.; Cao, G. Nanostructured carbon for energy storage and conversion. Nano Energy 2012, 1, 195-220. [CrossRef]

10. Xia, W.; Mahmood, A.; Zou, R.; Xu, Q. Metal-organic frameworks and their derived nanostructures for electrochemical energy storage and conversion. Energy Environ. Sci. 2015, 8, 1837-1866. [CrossRef]

11. Zhao, Q.; Yan, Z.; Chen, C.; Chen, J. Spinels: Controlled Preparation, Oxygen Reduction/Evolution Reaction Application, and Beyond. Chem. Rev. 2017, 117, 10121-10211. [CrossRef]

12. Riley, B.J.; Chun, J.; Um, W.; Lepry, W.C.; Matyas, J.; Olszta, M.J.; Li, X.; Polychronopoulou, K.; Kanatzidis, M.G. Chalcogen-based aerogels as sorbents for radionuclide remediation. Environ. Sci. Technol. 2013, 47, 7540-7547. [CrossRef] [PubMed] 
13. Polychronopoulou, K.; Malliakas, C.D.; He, J.; Kanatzidis, M.G. Selective Surfaces: Quaternary $\mathrm{Co}(\mathrm{Ni}) \mathrm{MoS}-$ Based Chalcogels with Divalent $(\mathrm{Pb} 2+, \mathrm{Cd} 2+, \mathrm{Pd} 2+)$ and Trivalent $(\mathrm{Cr} 3+, \mathrm{Bi} 3+)$ Metals for Gas Separation. Chem. Mater. 2012, 24, 3380-3392. [CrossRef]

14. Yuhas, B.D.; Prasittichai, C.; Hupp, J.T.; Kanatzidis, M.G. Enhanced Electrocatalytic Reduction of CO2with Ternary Ni-Fe4S4and Co-Fe4S4-Based Biomimetic Chalcogels. J. Am. Chem. Soc. 2011, 133, 15854-15857. [CrossRef] [PubMed]

15. Lubitz, W.; Tumas, W. Hydrogen: An Overview. Chem. Rev. 2007, 107, 3900-3903. [CrossRef] [PubMed]

16. Zhang, C.; Bhoyate, S.; Hyatt, M.; Neria, B.L.; Siam, K.; Kahol, P.; Ghimire, M.; Mishra, S.; Perez, F.; Gupta, R.K. Nitrogen-doped flexible carbon cloth for durable metal free electrocatalyst for overall water splitting. Surf. Coat. Technol. 2018, 347, 407-413. [CrossRef]

17. Tang, D.; Liu, J.; Wu, X.; Liu, R.; Han, X.; Han, Y.; Huang, H.; Liu, Y.; Kang, Z. Carbon Quantum Dot/NiFe Layered Double-Hydroxide Composite as a Highly Efficient Electrocatalyst for Water Oxidation. ACS Appl. Mater. Interfaces 2014, 6, 7918-7925. [CrossRef] [PubMed]

18. May, K.J.; Perry, E.E.; Lee, Y.; Suntivich, J.; Shao-Horn, Y. Synthesis and Activities of Rutile IrO 2 and RuO 2 Nanoparticles for Oxygen Evolution in Acid and Alkaline Solutions. J. Phys. Chem. Lett. 2012, 3, 399-404. [CrossRef]

19. Popczun, E.J.; McKone, J.R.; Read, C.G.; Biacchi, A.J.; Wiltrout, A.M.; Lewis, N.S.; Schaak, R.E. Nanostructured Nickel Phosphide as an Electrocatalyst for the Hydrogen Evolution Reaction. J. Am. Chem. Soc. 2013, 135, 9267-9270. [CrossRef]

20. Beidaghi, M.; Gogotsi, Y. Capacitive energy storage in micro-scale devices: Recent advances in design and fabrication of micro-supercapacitors. Energy Environ. Sci. 2014, 7, 867. [CrossRef]

21. Merlet, C.; Rotenberg, B.; Madden, P.A.; Taberna, P.-L.; Simon, P.; Gogotsi, Y.; Salanne, M. On the molecular origin of supercapacitance in nanoporous carbon electrodes. Nat. Mater. 2012, 11, 306-310. [CrossRef]

22. Zhou, W.; Cao, X.; Zeng, Z.; Shi, W.; Zhu, Y.; Yan, Q.; Liu, H.; Wang, J.; Zhang, H. One-step synthesis of $\mathrm{Ni}_{3} \mathrm{~S}_{2}$ nanorod@Ni(OH)$)_{2}$ nanosheet core-shell nanostructures on a three-dimensional graphene network for high-performance supercapacitors. Energy Environ. Sci. 2013, 6, 2216-2221. [CrossRef]

23. Dong, C.; Wang, Y.; Xu, J.; Cheng, G.; Yang, W.; Kou, T.; Zhang, Z.; Ding, Y. 3D binder-free Cu2O@Cu nanoneedle arrays for high-performance asymmetric supercapacitors. J. Mater. Chem. A 2014, 2, 18229-18235. [CrossRef]

24. Li, H.B.; Yu, M.H.; Wang, F.X.; Liu, P.; Liang, Y.; Xiao, J.; Wang, C.X.; Tong, Y.X.; Yang, G.W. Amorphous nickel hydroxide nanospheres with ultrahigh capacitance and energy density as electrochemical pseudocapacitor materials. Nat. Commun. 2013, 4, 1894. [CrossRef] [PubMed]

25. Yang, X.; Xu, K.; Zou, R.; Hu, J. A Hybrid Electrode of $\mathrm{Co}_{3} \mathrm{O}_{4} @ P$ Py Core/Shell Nanosheet Arrays for High-Performance Supercapacitors. Nano-Micro Lett. 2016, 8, 143. [CrossRef] [PubMed]

26. Zhou, C.; Zhang, Y.; Li, Y.; Liu, J. Construction of High-Capacitance 3D CoO@Polypyrrole Nanowire Array Electrode for Aqueous Asymmetric Supercapacitor. Nano Lett. 2013, 13, 2078-2085. [CrossRef] [PubMed]

27. Grosvenor, A.P.; Biesinger, M.C.; Smart, R.S.; McIntyre, N.S. New interpretations of XPS spectra of nickel metal and oxides. Surf. Sci. 2006, 600, 1771-1779. [CrossRef]

28. Biesinger, M.C.; Payne, B.P.; Grosvenor, A.P.; Lau, L.W.; Gerson, A.R.; Smart, R.S. Resolving surface chemical states in XPS analysis of first row transition metals, oxides and hydroxides: Cr, Mn, Fe, Co and Ni. Appl. Surf. Sci. 2011, 257, 2717-2730. [CrossRef]

29. Biesinger, M.C.; Payne, B.P.; Lau, L.W.M.; Gerson, A.; Smart, R.S.C. X-ray photoelectron spectroscopic chemical state quantification of mixed nickel metal, oxide and hydroxide systems. Surf. Interface Anal. 2009, 41, 324-332. [CrossRef]

30. Grosvenor, A.P.; Kobe, B.A.; Biesinger, M.C.; McIntyre, N.S.; Grosvenor, A. Investigation of multiplet splitting of Fe 2p XPS spectra and bonding in iron compounds. Surf. Interface Anal. 2004, 36, 1564-1574. [CrossRef]

31. Smith, R.D.L.; Prévot, M.S.; Fagan, R.D.; Trudel, S.; Berlinguette, C.P. Water Oxidation Catalysis: Electrocatalytic Response to Metal Stoichiometry in Amorphous Metal Oxide Films Containing Iron, Cobalt, and Nickel. J. Am. Chem. Soc. 2013, 135, 11580-11586. [CrossRef] [PubMed]

32. Wittstock, G.; Kartio, I.; Hirsch, D.; Kunze, S.; Szargan, R. Oxidation of Galena in Acetate Buffer Investigated by Atomic Force Microscopy and Photoelectron Spectroscopy. Langmuir 1996, 12, 5709-5721. [CrossRef]

33. Brion, D. Etude par spectroscopie de photoelectrons de la degradation superficielle de FeS2, CuFeS2, ZnS et PbS a l'air et dans l'eau. Appl. Surf. Sci. 1980, 5, 133-152. [CrossRef] 
34. Buckley, A.; Woods, R. X-ray photoelectron spectroscopy of oxidized pyrrhotite surfaces. Appl. Surf. Sci. 1985, 22, 280-287. [CrossRef]

35. Buckley, A.; Woods, R. X-ray photoelectron spectroscopy of oxidised pyrrhotite surfaces. Appl. Surf. Sci. 1985, 20, 472-480. [CrossRef]

36. Piontek, S.; Andronescu, C.; Zaichenko, A.; Konkena, B.; Puring, K.j.; Marler, B.; Antoni, H.; Sinev, I.; Muhler, M.; Mollenhauer, D.; et al. Influence of the Fe:Ni Ratio and Reaction Temperature on the Efficiency of (FexNi1-x)9S8 Electrocatalysts Applied in the Hydrogen Evolution Reaction. ACS Catal. 2018, 8, 987-996. [CrossRef]

37. Shalvoy, R.B.; Reucroft, P.J. Characterization of a sulfur-resistant methanation catalyst by XPS. J. Vac. Sci. Technol. 1979, 16, 567-569. [CrossRef]

38. Dickinson, T.; Povey, A.F.; Sherwood, P.M.A. Dissolution and passivation of nickel. An X-ray photoelectron spectroscopic study. J. Chem. Soc. Faraday Trans. 1 Phys. Chem. Condens. Phases 1977, 73, 327. [CrossRef]

39. Van Der Heide, H.; Hemmel, R.; Van Bruggen, C.; Haas, C. X-ray photoelectron spectra of 3d transition metal pyrites. J. Solid State Chem. 1980, 33, 17-25. [CrossRef]

40. Seah, M.P. An accurate and simple universal curve for the energy-dependent electron inelastic mean free path. Surf. Interface Anal. 2012, 44, 497-503. [CrossRef]

41. Sultana, U.K.; He, T.; Du, A.; O'Mullane, A.P. An amorphous dual action electrocatalyst based on oxygen doped cobalt sulfide for the hydrogen and oxygen evolution reactions. RSC Adv. 2017, 7, 54995-55004. [CrossRef]

42. Jin, C.; Lu, F.; Cao, X.; Yang, Z.; Yang, R. Facile synthesis and excellent electrochemical properties of NiCo2O4 spinel nanowire arrays as a bifunctional catalyst for the oxygen reduction and evolution reaction. J. Mater. Chem. A 2013, 1, 12170. [CrossRef]

43. Kim, D.-Y.; Ghodake, G.S.; Maile, N.C.; Kadam, A.A.; Lee, D.S.; Fulari, V.J.; Shinde, S.K. Chemical synthesis of hierarchical NiCo2S4 nanosheets like nanostructure on flexible foil for a high performance supercapacitor. Sci. Rep. 2017, 7, 9764. [CrossRef] [PubMed]

44. Chen, H.; Hu, L.; Chen, M.; Yan, Y.; Wu, L. Nickel-Cobalt Layered Double Hydroxide Nanosheets for High-performance Supercapacitor Electrode Materials. Adv. Funct. Mater. 2014, 24, 934. [CrossRef]

45. Li, Y.; Cao, L.; Qiao, L.; Zhou, M.; Yang, Y.; Xiao, P.; Zhang, Y. Ni-Co sulfide nanowires on nickel foam with ultrahigh capacitance for asymmetric supercapacitors. J. Mater. Chem. A 2014, 2, 6540-6548. [CrossRef]

(C) 2019 by the authors. Licensee MDPI, Basel, Switzerland. This article is an open access article distributed under the terms and conditions of the Creative Commons Attribution (CC BY) license (http://creativecommons.org/licenses/by/4.0/). 